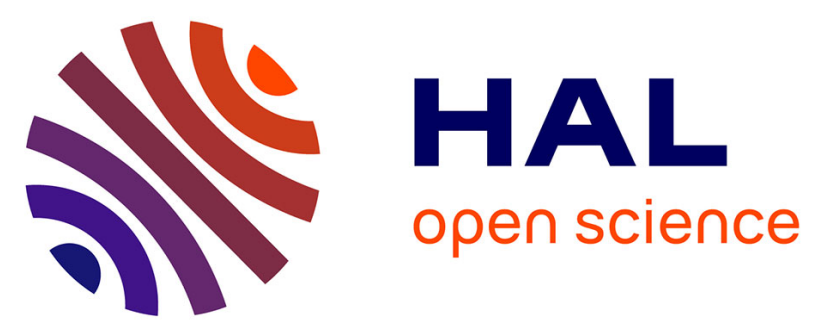

\title{
Collision cross sections of negative cluster ions of phosphoric acid in N2 determined by drift tube ion mobility and their use in travelling wave ion mobility
}

Hélène Lavanant, Michael Groessl, Carlos Afonso

\section{- To cite this version:}

Hélène Lavanant, Michael Groessl, Carlos Afonso. Collision cross sections of negative cluster ions of phosphoric acid in N2 determined by drift tube ion mobility and their use in travelling wave ion mobility. International Journal of Mass Spectrometry, 2019, 442, pp.14-22. 10.1016/j.ijms.2019.04.009 . hal-02330462

HAL Id: hal-02330462

https://hal-normandie-univ.archives-ouvertes.fr/hal-02330462

Submitted on 22 Oct 2021

HAL is a multi-disciplinary open access archive for the deposit and dissemination of scientific research documents, whether they are published or not. The documents may come from teaching and research institutions in France or abroad, or from public or private research centers.
L'archive ouverte pluridisciplinaire HAL, est destinée au dépôt et à la diffusion de documents scientifiques de niveau recherche, publiés ou non, émanant des établissements d'enseignement et de recherche français ou étrangers, des laboratoires publics ou privés.

\section{(ㄷ)(1) $\$$}

Distributed under a Creative Commons Attribution - NonCommerciall 4.0 International 
Collision cross sections of negative cluster ions of phosphoric acid in $\mathrm{N}_{2}$ determined by drift tube ion mobility and their use in travelling wave ion mobility

Hélène Lavanant ${ }^{\dagger}, *$ Michael Groess ${ }^{\ddagger \S}$, Carlos Afonso $^{\dagger}$

${ }^{+}$Normandie Univ, UNIROUEN, INSA Rouen, CNRS, COBRA, 76000 Rouen, France

${ }^{\ddagger}$ Department of Nephrology and Hypertension and Department of BioMedical Research, Inselspital, Bern University Hospital, University of Bern, Switzerland

$\S$ Tofwerk AG, Uttigenstr. 22, 3600 Thun, Switzerland

* Corresponding author

Université de Rouen

IRCOF, 1 Rue Tesnière,

76821 Mont-Saint-Aignan Cedex, France

Tel: +33235522932

helene.lavanant@univ-rouen.fr. 


\section{ABSTRACT}

Travelling wave ion mobility usually uses a calibration procedure to determine collision cross sections. Here, we investigate phosphoric acid cluster anions as possible calibrants to increase the pool of reference ions for singly and multiply charged anions with nitrogen as drift gas.

Phosphoric acid solutions ( 5 to $50 \mathrm{mM}$ ) in water and acetonitrile were analyzed using electrospray ionization in the negative ion mode. Collision cross sections were obtained using an IMS-TOF drift tube ion mobility mass spectrometer (Tofwerk, Thun, Switzerland) (DTIMS-MS) on which we varied the electric field. Twenty-six collision cross sections from DTIMS-MS in nitrogen gas, termed ${ }^{\mathrm{DT}} \mathrm{CCS}\left(\mathrm{N}_{2}\right)$, were obtained for singly, doubly and triply charged phosphoric acid cluster anions which range from 146 to $530 \AA^{2}$. Reduced mobilites $\mathrm{K}_{0}$ ranged from 0.767 to $1.435 \mathrm{~cm}^{2} \mathrm{~V}^{-1} \mathrm{~s}^{-1}$ for singly charged cluster anions, 1.177 to 1.006 $\mathrm{cm}^{2} \mathrm{~V}^{-1} \mathrm{~s}^{-1}$ and 1.250 to $1.0143 \mathrm{~cm}^{2} \mathrm{~V}^{-1} \mathrm{~s}^{-1}$ for doubly and triply charged cluster anions, respectively. The ${ }^{\mathrm{DT}} \mathrm{CCS}\left(\mathrm{N}_{2}\right)$ were found fitted to a power function $80 n^{0.51}$ where $n$ is the aggregation number.

Ion mobility mass spectrometry measurements were also carried out on a travelling wave ion mobility mass spectrometry (TWIMS-MS) device (SYNAPT G2 HDMS, Waters Corp., Manchester, UK). The ${ }^{\mathrm{DT}} \mathrm{CCS}\left(\mathrm{N}_{2}\right)$ were well correlated to the drift times measured on the TWIM instrument ( $R^{2}$ above 0.9999$)$. The correlation function was found to depend on the charge state of the ions. Accuracy tests evidenced a systematic error of 9 to $11 \AA^{2}$ (4-6\%) on singly charged ions of polyalanine, dextran and hexakis(fluoroalkoxy)phosphazine compared to literature values. Although absolute values were shifted, CCS differences were preserved.

Keywords

Drift tube ion mobility, collision cross section, phosphoric acid, cluster ions, travelling wave ion mobility, calibration

Graphical Abstract

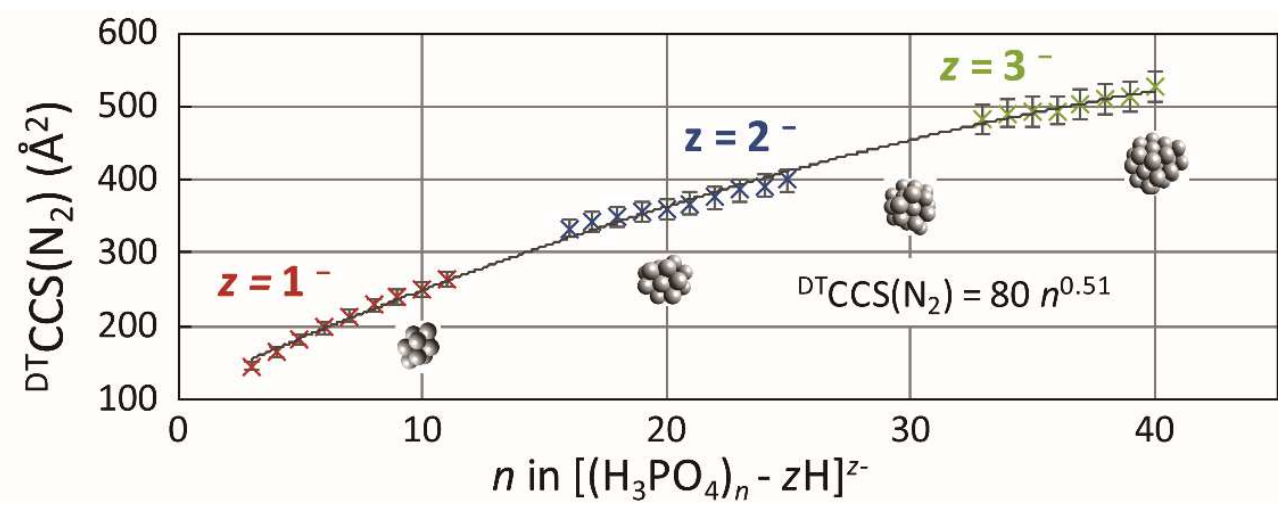




\section{INTRODUCTION}

With the development of commercial instruments, the coupling of ion mobility and mass spectrometry is spreading as supplemental method to be used for compound identification or structural characterization to mass spectrometry. ${ }^{1,2}$ Indeed, ion mobility depends largely on the charge and the collision cross section (CCS or $\Omega$ ) of the ions that is related to their conformations in the gas phase.

Conventional uniform electric field drift tube ion mobility spectrometry (DTIMS) enables the direct determination of ion mobility $\mathrm{K}$ and $\mathrm{CCS}$, usually by stepping the electric field. Other ion mobility techniques, such as travelling wave ion mobility (TWIMS) ${ }^{3}$ or trapped ion mobility (TIMS) ${ }^{4}$ require the tuning of a higher number of parameters and use reference ions and calibration to determine the CCS. ${ }^{5,6,7,8}$

For positive ions, many reference calibrants exist, ${ }^{9}$ for which CCS were previously determined experimentally with DTIMS and usually helium as the drift gas (noted ${ }^{D T} \mathrm{CCS}_{\mathrm{He}}$ ). The pool of reference ions is smaller for the negative ion mode ${ }^{10,11,12}$, especially for multiply charged ions and with nitrogen as drift gas. Furthermore, there still remains, at this day, many questions and discussions on the different choice of CCS reference (ion and drift gas) and on the calibration procedure for travelling wave ion mobility. ${ }^{13,14,15}$

Cluster ions are readily produced using direct infusion of salt solutions with an electrospray ion source and are routinely used for calibration of mass analyzers. ${ }^{16,17,18,19,20}$ A number of ionic clusters derived from alkali halides salts, $21,22,23$ ionic liquids $24,25,26,27$ and transition metal oxides $28,29,30,31,32,33$ have been studied by drift tube ion mobility mainly and differential mobility analysis-time-of-flight mass spectrometry. Since a first study in 2014, ${ }^{34}$ we have started studying negative phosphoric acid cluster ions in view of investigating their potential as reference for the calibration of the TWIMS.

Here, we determined the CCS values of twenty-six negatively charged phosphoric acid cluster ions, singly, doubly and triply charged with a drift-tube ion mobility-time-of-flight mass spectrometer, at $32.6^{\circ} \mathrm{C}$, and using nitrogen as the drift gas. The ${ }^{\mathrm{DT}} \mathrm{CCS}\left(\mathrm{N}_{2}\right)$ values were then used as reference for calibration of a TWIMS device and the resulting calibration was tested for accuracy.

\section{METHODS}

The phosphoric acid used was an $85 \%$ weight solution in water $(d=1.680)$ from Acros Organics (through Fisher Scientific France, Illkirch, France). LC-MS grade acetonitrile were purchased from VWR (Fontenay-sous-bois, France). Deionized water (18 $\mathrm{M} \Omega$ ) was obtained from a Milli-Q apparatus (Millipore, Bedford, MA, USA). $50 \mathrm{mM}$ and $5 \mathrm{mM}$ solutions were prepared in water/acetonitrile $50 / 50$ and $(0.35 \%$ to $0.035 \%$ volume of the phosphoric acid solution). Solutions of Poly-DL-alanine (mol wt 1000-5000 purchased from Sigma-Aldrich, St. Louise, USA) at a concentration of $10 \mu \mathrm{M}$ and dextran enzymatic synthesis ( $\mathrm{Mr}$ 1500, Fluka Analytical, Sigma-Aldrich, Denmark) at a concentration of $100 \mu \mathrm{M}$ were prepared in water/acetonitrile 50/50 v/v. The solution of tune mix (from Agilent Technologies, Santa Clara, CA) was obtained by diluting to $1: 4$ with $95 \%$ acetonitrile in water. 
All drift tube ion mobility - mass spectrometry measurements (DTIMS-MS) were carried out on a Tofwerk IMS-TOF instrument (Thun, Switzerland). The system comprises an electrospray ionization (ESI) source, a $10 \mathrm{~cm}$ desolvation tube, a $20.56 \mathrm{~cm}$ drift tube (both made from resistive glass) and a Tofwerk time of flight HTOF analyzer (TOF-MS) with a two-stage interface to the IMS, as described in detail elsewhere. ${ }^{35}$ Desolvation and drift tubes were thermostated at $32.6{ }^{\circ} \mathrm{C}$ with nitrogen as the buffer gas. Drift-tube pressure was set at 1000 mbar $\left(\mathrm{N}_{2}\right)$. The pressure sensor is a JUMO MIDAS C08 (JUMO GmbH \& Co. KG,Fulda, Germany) whose accuracy is given as $0.5 \%$ and the temperature sensor is a generic k-type thermocouple with an accuracy of $+-0.75 \%$. Ion mobility separation was carried out at field strengths of ca. 300 to $460 \mathrm{~V} \mathrm{~cm}^{-1}$ (reduced electric field strength between 1 and $2 \mathrm{Td}$ ). Samples were introduced directly into the ESI source using a syringe pump at $1 \mu \mathrm{l} \mathrm{min}{ }^{-1}$. The instrument was operated from $\mathrm{m} / \mathrm{z} 50$ to 1500 in negative ion mode with a measurement time of 2 to $5 \mathrm{~min}$ at each field strength. The mass spectrometer was calibrated internally. Ion optics were set as to minimize dissociation between the drift tube and the TOF analyzer (Table S1). Raw IMS-TOF data was post-processed using IMS Viewer and Tofware (Tofwerk, Switzerland) with a denoise and sharpness features set to 1 . The instrument uses a Hadamard-type multiplexing method. In addition to increasing sensitivity, properties of the time domain data can be exploited to increase both signal to noise ratio and effective resolving power.

For reduced ion mobility and collision cross section measurements, drift-tube ion mobility drift times were measured at five different field strengths (potential differences from 6.2 to $9.4 \mathrm{kV}$ ). With a uniform field, the slope of the drift time $v s$ the reciprocal of the potential difference is the square of the tube length divided by the ion mobility $K\left(L^{2} / K\right)$. The ion mobility $\mathrm{K}$ can then be converted to a reduced ion mobility $\mathrm{K}_{0}$ and, using the Mason Schamp equation, ${ }^{36}$ to a collision cross section in $\mathrm{N}_{2}$, that we will note ${ }^{\mathrm{DT}} \mathrm{CCS}\left(\mathrm{N}_{2}\right)$. Standard uncertainties for the measurement of instrumental parameters were given as follows: pressure \pm 5 mbar $(0.5 \%)$, temperature $\pm 3 \mathrm{~K}(0.75 \%)$, drift voltage $\pm 2 \mathrm{~V}(0.03 \%)$. The observed relative standard errors for the slopes of the drift time $v s$ the reciprocal of the potential difference were less than $0.5 \%$. The exact length of the drift tube is $20.555 \mathrm{~cm}$ but due to possible edge effects of the electric field, we cautiously estimated an expanded uncertainty of $\pm 3 \mathrm{~mm}$ for the effective electric field length, by doubling results observed by Stow et al on effective length. ${ }^{37}$ Then, applying a type B evaluation of standard uncertainty and propagation of error, we found this latter expanded uncertainty had a dominant effect and resulted in a combined relative expanded uncertainty of $3 \%$ on $\mathrm{K}_{0}$ and CCS values (level of confidence of approximately $95 \%)$.

Travelling wave ion mobility and mass spectra were recorded using a SYNAPT G2 HDMS (Waters Corp., Manchester, UK) fitted with an electrospray ionization source. ESI mass spectra were acquired over the $m / z 50-1600$ or 50-4000 range, in the negative ion modes. Values for the capillary emitter were $2.7 \mathrm{kV}$ and sampling cone $60 \mathrm{~V}$. The source temperature was set at $90^{\circ} \mathrm{C}$. Nitrogen gas at a temperature of $250^{\circ} \mathrm{C}$ and a flow rate of 500 $\mathrm{L} / \mathrm{h}$ was used to assist desolvation in the ESI source. The solution was infused at a flow rate 
of $5 \mu \mathrm{L} / \mathrm{min}$ using the spectrometer sample pump. Gas flow rates were set at $20 \mathrm{~mL} / \mathrm{min}$ in the source stacked ring ion guide, $180 \mathrm{~mL} / \mathrm{min}$ in the helium cell and $70 \mathrm{~mL} / \mathrm{min}$ in the ion mobility cell. Trap and transfer collision energies were set to $5 \mathrm{~V}$ and $0 \mathrm{~V}$ respectively. Travelling wave velocities were set to $350 \mathrm{~m} / \mathrm{s}$ and the wave height at 15 or $20 \mathrm{~V}$, to minimize hydrogen bond disruption. Direct current voltages in the trap and IMS cells were also adjusted to minimize fragmentation (Table S2). Data treatment was carried out with Mass Lynx (4.1).

Measurements were duplicated on different days to eliminate aberrant values; the results presented here are from single experiments with type B uncertainties.

All ion mobility spectra (DTIMS and TWIMS) were fitted to Gaussian curves with OriginPro 9.1 to obtain experimental drift times with maximum accuracy.

\section{RESULTS AND DISCUSSION}

\section{Drift-tube ion mobility of phosphoric acid cluster ions}

With phosphoric acid cluster ions, the process of assignment of ion mobility peaks to the correct ion was complicated by two facts. First, phosphoric cluster ions, as they are hydrogen bonded cluster ions, tend to dissociate very easily. When dissociation happens after the ion mobility device, the extracted ion mobility spectrum (EIM, also called arrival time distributions or ATD) of a given $\mathrm{m} / \mathrm{z}$ corresponding to a cluster size with $n$ phosphoric acid molecules (that we will refer to a P\# $\left.n^{2-}\right)$ also contains peak of larger clusters $(n+1, n+2 \ldots)$. Indeed, such larger cluster ions are precursor ions that dissociated by losing one or two neutral $\mathrm{H}_{3} \mathrm{PO}_{4}$ molecules after the ion mobility device but before the time of flight analyzer to give the $P \# n^{2-}$ cluster ion. This process is classically observed for many cluster ions ${ }^{21}$ and has been termed neutral evaporation by Juan Fernandez de la Mora et al. ${ }^{38,39}$ Dissociation involving loss of charge may also occur from large multiply charged cluster ions, and in that case it may be termed ion evaporation. Second, a given $\mathrm{m} / \mathrm{z}$ classically corresponds to multimers of mass $m, 2 m$ and $3 m$ with charge states $[\mathrm{M}-\mathrm{H}]^{-},[2 \mathrm{M}-2 \mathrm{H}]^{2-}$ and $[3 \mathrm{M}-3 \mathrm{H}]^{3-}$ respectively and each multimer appears as a different ion mobility peak. These multimers may of course also be distinguished by their isotopic pattern on the mass spectrum, which for phosphoric acid cluster ions, mainly arises from the $0.2 \%$ relative abundance of ${ }^{18} \mathrm{O}$, as $\mathrm{P}$ has one unique isotope ${ }^{31} \mathrm{P}$. The peaks of the isotopic distribution are thus spaced by $\mathrm{m} / \mathrm{z} 2$, $1,0.67$ for the singly, doubly and triply charged, respectively (Figure S1).

Figure 1 shows the EIM spectra of two series of six and eight $m / z$ values corresponding to a

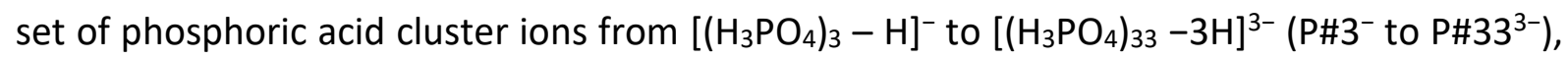
at a potential difference of $8.6 \mathrm{kV}$. The resolving power (calculated form the FWHM) of all ion mobility signals was around 130. By overlaying the different EIM spectra, the signals of dissociation products of larger clusters could be assigned. Indeed, correct peak assignment could be unambiguously obtained by comparing the EIM spectra of the $m / z$ values of clusters ions of adjacent aggregation numbers (i.e. $n$ and $n+1$ ). The peak that is uniquely present in the EIM spectrum from the $m / z$ value of $P \# n^{z-}$ and not $P \#(n+1)^{z-}$ may be assigned to the intact $P \# n^{z-}$ cluster ion. For example, the EIM spectrum of $m / z 488.88$ (or $m / z$ value of P\#5 $5^{-}$represented in magenta in Figure 1a), included a signal at $39.04 \mathrm{~ms}$ from the intact P\#5- 
cluster ion, as well as a significant peak at a higher drift time (42.67 ms). This signal at 42.67 ms was also clearly visible in the EIM spectrum of $m / z 586.85\left(\mathrm{~m} / z\right.$ value of P\#6 $6^{-}$in green in Figure 1a). The signal at $42.67 \mathrm{~ms}$ corresponding to the P\#6- cluster ion is present in the EIM spectrum of $\mathrm{m} / \mathrm{z} 488.88$ because $\mathrm{P \# 6}^{-}$is a precursor ion of $\mathrm{P \# 5^{- }}$, and it fragments to $\mathrm{P \# 5^{- }}$ (i.e. $m / z$ 488.88) after the ion mobility device.

(a)

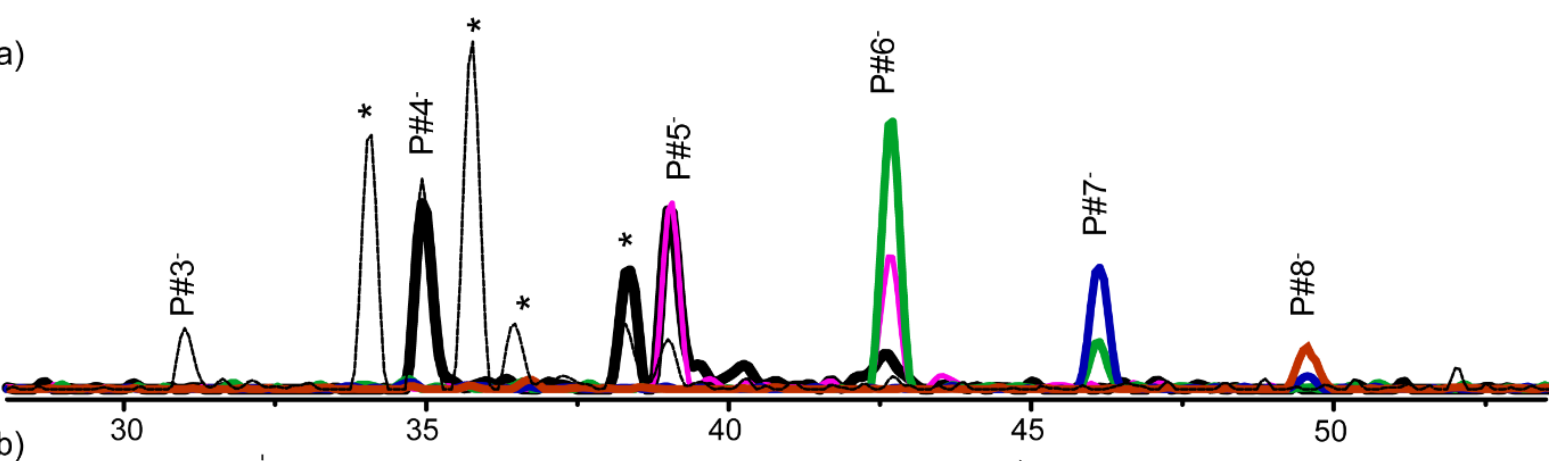

(b)

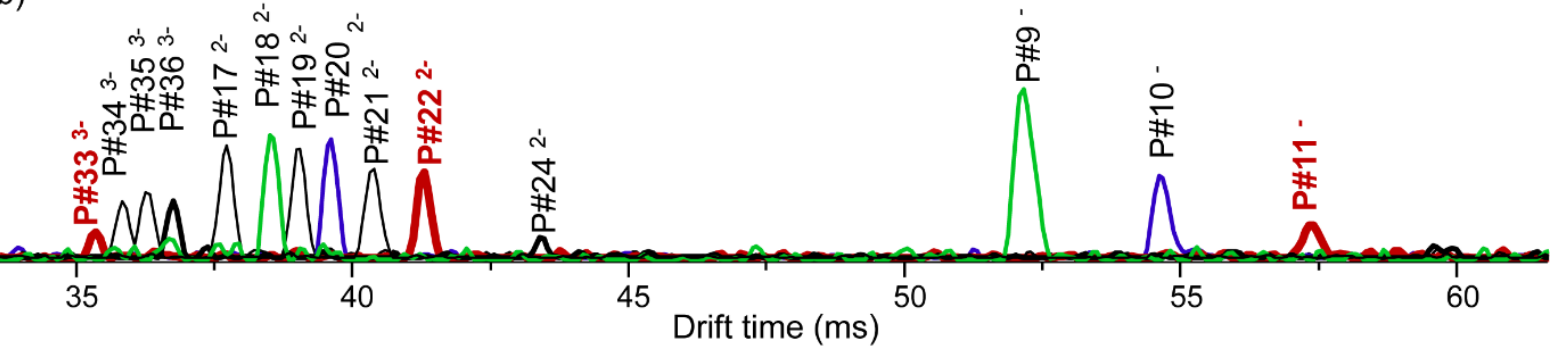

Figure 1. (a) Extracted ion mobility spectra of m/z 293 (thin black), 391 (thick black), 489 (magenta), 586 (green), 587(blue), and 685 (red) corresponding phosphoric acid cluster ions from $\left[\left(\mathrm{H}_{3} \mathrm{PO}_{4}\right)_{3}-\mathrm{H}^{-}\right.$to $\left[\left(\mathrm{H}_{3} \mathrm{PO}_{4}\right)_{8}-\mathrm{H}^{-}\left(\mathrm{PH}^{-}\right.\right.$to $\left.\mathrm{PH} 8^{-}\right)$respectively.

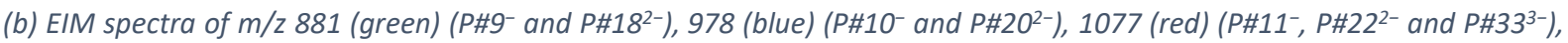

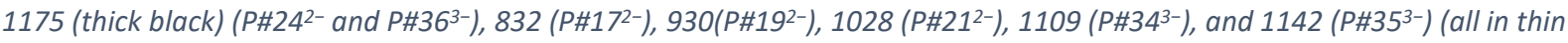
black). EIM spectra are overlapped and were recorded at a nominal potential difference of $8.6 \mathrm{kV}$ in the ion mobility region. Asterisks (*) refer to peaks that could not be attributed. The omitted $y$ axis is the signal intensity in arbitrary units normalized to the highest peak on display.

The amount of dissociation deduced from these observations depends on the size of the cluster ion. The EIM spectrum of $\mathrm{m} / \mathrm{z} 292.92$ contained many different peaks beside the intact P\#3- cluster ion at 31.02 ms. These peaks at higher drift times could not be attributed except for the signal corresponding to $\mathrm{PH}^{-}$at $34.96 \mathrm{~ms}$ which appeared in the EIM of $\mathrm{m} / \mathrm{z}$ 390.90. Although these unattributed peaks were a problem at low $m / z$, it was not the case for the higher $\mathrm{m} / \mathrm{z}$ as the amount of dissociation was found to decrease with increasing cluster size. In the EIM spectrum of $m / z 684.83$ (blue trace in Figure 1a) the amount of P\#8-, as precursor ion of $\mathrm{P \# 7}^{-}$, was very small and in the EIM spectrum of $\mathrm{m} / \mathrm{z} 782.81$, one signal for $\mathrm{P} \# 8^{-}$was detected at $49.56 \mathrm{~ms}$ and no peaks at higher drift times were observed.

For larger cluster sizes, multiply charged cluster ions appeared on the EIM spectra. The EIM spectrum of $\mathrm{m} / \mathrm{z} 880.78$ (represented in green in figure $1 \mathrm{~b}$ ) very distinctively showed two peaks corresponding to $\mathrm{P \# 9}^{-}(52.16 \mathrm{~ms})$ and $\mathrm{P \# 18^{2- }}$ (38.53 ms). A P\#172- cluster ion could also be detected at $37.72 \mathrm{~ms}$. Here again, the peaks could be unambiguously assigned by comparing the extracted ion mobility spectra of the $\mathrm{m} / \mathrm{z}$ values of clusters ions of adjacent aggregation numbers: this overlay highlighted a pattern for the drift times of cluster ions of consecutive aggregation numbers and similar charge state, increasing confidence in the peak assignments. Noteworthy, in the EIM spectrum of $m / z$ 831.80, a P\#17 ${ }^{2-}$ cluster was observed, making 17 the threshold cluster number for which doubly charged cluster ions 
could be unambiguously detected. The EIM spectrum of $\mathrm{m} / \mathrm{z} 1076.73$ showed peaks corresponding to $\mathrm{P} \# 11^{-}, \mathrm{P} \# 22^{2-}$ and $\mathrm{P} \# 33^{3-}$. In fact, 33 was the threshold cluster number for which triply charged cluster ions could be detected in our experiments. Charge threshold and multiple peaks due to post-ion mobility dissociation may also be visualized in twodimensional IMS-MS color map (Figure S2).

To determine collision cross sections in nitrogen gas in the drift tube ion mobility instrument, termed ${ }^{\mathrm{DT}} \mathrm{CCS}\left(\mathrm{N}_{2}\right)$, experiments were carried out at five different potential differences on the ion mobility drift-tube (Figure 2 and Figure S3-S10). After unambiguous assignment of the peaks corresponding to the intact cluster ions, the drift time of each cluster ions were measured by fitting a Gaussian function on the assigned ion mobility peaks. For lower field strengths, however, the intensities of doubly and triply charged cluster ions were too low for reliable drift time measurements.

(a)

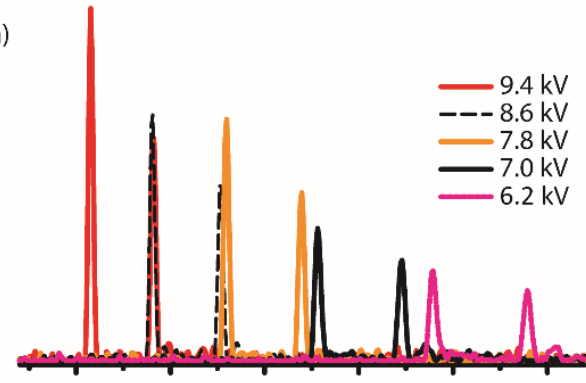

(c)

(e)

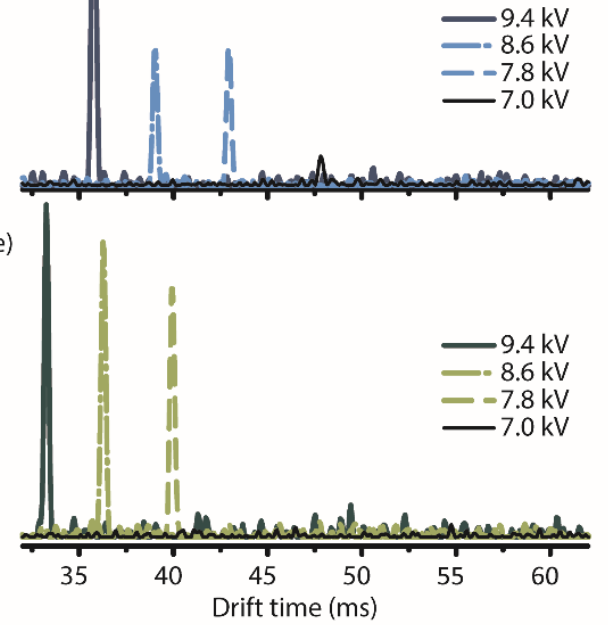

(b)

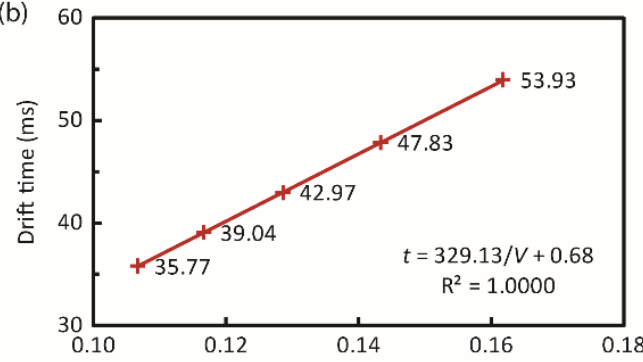

(d)
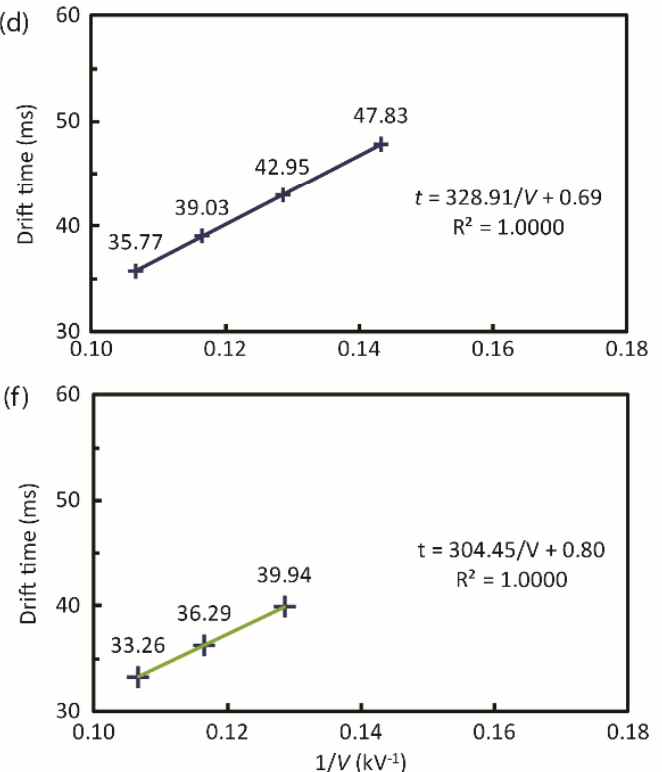

Figure 2. (a) Extraction ion mobility spectra of $\mathrm{m} / \mathrm{z} 489$ (P\#5-) at five different electric field strengths corresponding to 9.4, 8.6, 7.8, 7.0 and $6.2 \mathrm{kV}$ potential difference. (b) Graph of drift times vs $1 / \mathrm{V}$ for $\mathrm{m} / \mathrm{z} 489$ (P\#5-). (c) EIM spectra of $\mathrm{m} / \mathrm{z} 930$ (P\#192-) at four field strength corresponding to 9.4, 8.6, 7.8 and $7.0 \mathrm{kV}$. (d) Graph of drift times vs $1 / \mathrm{V} \mathrm{for} \mathrm{m/z} 930$ (P\#192-).

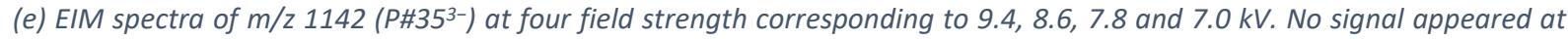

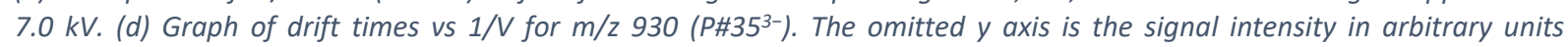
normalized to the peak observed at $9.4 \mathrm{kV}$ potential difference.

The plots of measured drift times vs the reciprocal of the potential difference thus include five points for singly charged, four points for doubly charged and three points for triply 
charged cluster ions. Nevertheless, the data always showed the expected linear correlation with a determination coefficient above 0.9999 (Figures S3-S10). As the slope of the linear regression of the drift times $v s$ the reciprocal of the potential difference is the square of the drift tube length divided by the ion mobility $\left(\mathrm{L}^{2} / \mathrm{K}\right)$, the ion mobility $\mathrm{K}$ could be derived and converted to a reduced ion mobility $\mathrm{K}_{0}$ or ${ }^{\mathrm{DT}} \mathrm{CCS}\left(\mathrm{N}_{2}\right)$ using the Mason Schamp equation. The results are presented in table 1.

Table 1. Reduced ion mobilities $K_{0}$ and collision cross section values in $N_{2}$ gas measured by drift-tube ion mobility mass spectrometry $\left({ }^{D T} \mathrm{CCS}\left(\mathrm{N}_{2}\right)\right)$ of twenty-six phosphoric acid cluster anions. The B type relative expanded uncertainties on these values was estimated at $\pm 3 \%$.

\begin{tabular}{|c|c|c|c|c|}
\hline Ion type & P\# & $m / z$ & $\begin{array}{l}\mathrm{K}_{0} \\
\left(\mathrm{~cm}^{2} \mathrm{~V}^{-1}\right. \\
\left.\mathrm{s}^{-1}\right)\end{array}$ & $\begin{array}{l}{ }^{D T} \operatorname{CCS}\left(\mathrm{N}_{2}\right) \\
\left(\AA^{2}\right)\end{array}$ \\
\hline \multirow{9}{*}[(\mathrm{H}_{3}\mathrm{PO}_{4})_{n}-\mathrm{H}]{$^{-}$} & 3 & 293 & 1.435 & 145.9 \\
\hline & 4 & 391 & 1.266 & 163.6 \\
\hline & 5 & 489 & 1.132 & 181.7 \\
\hline & 6 & 587 & 1.035 & 197.7 \\
\hline & 7 & 685 & 0.957 & 213.2 \\
\hline & 8 & 783 & 0.891 & 228.5 \\
\hline & 9 & 881 & 0.847 & 240.0 \\
\hline & 10 & 979 & 0.807 & 251.5 \\
\hline & 11 & 1077 & 0.767 & 264.2 \\
\hline \multirow{9}{*}[(\mathrm{H}_{3}\mathrm{PO}_{4})_{n}-2\mathrm{H}]{$^{2-}$} & 17 & 832 & 1.177 & 342.7 \\
\hline & 18 & 881 & 1.150 & 350.5 \\
\hline & 19 & 930 & 1.133 & 355.8 \\
\hline & 20 & 979 & 1.118 & 360.3 \\
\hline & 21 & 1028 & 1.097 & 367.1 \\
\hline & 22 & 1077 & 1.072 & 375.5 \\
\hline & 23 & 1126 & 1.032 & 386.4 \\
\hline & 24 & 1175 & 1.031 & 390.4 \\
\hline & 25 & 1224 & 1.006 & 399.7 \\
\hline \multirow{8}{*}[(\mathrm{H}_{3}\mathrm{PO}_{4})_{n}-3\mathrm{H}]{$^{3-}$} & 33 & 1077 & 1.250 & 482.3 \\
\hline & 34 & 1109 & 1.229 & 490.4 \\
\hline & 35 & 1142 & 1.224 & 492.4 \\
\hline & 36 & 1175 & 1.219 & 494.4 \\
\hline & 37 & 1207 & 1.199 & 502.5 \\
\hline & 38 & 1240 & 1.184 & 508.7 \\
\hline & 39 & 1272 & 1.171 & 514.1 \\
\hline & 40 & 1305 & 1.143 & 526.7 \\
\hline
\end{tabular}

The type $B$ relative expanded uncertainty on these values were cautiously estimated to be $\pm 3 \%$ (level of confidence of approximately $95 \%$ ). Indeed, studies by Stow et al ${ }^{37}$ showed "effective" length of the drift tube could differ from the geometrical length by $1.6 \mathrm{~mm}$. We 
chose to double this number to $3 \mathrm{~mm}$, as a rough evaluation of any edge effects of the electric field. The reduced ion mobility $\mathrm{K}_{0}$ range was much larger for singly charged cluster anions ( 0.77 to $1.4 \mathrm{~cm}^{2} \mathrm{~V}^{-1} \mathrm{~s}^{-1}$ ) while the doubly and triply charged cluster anions cover only $30 \%$ and $16 \%$ of that range respectively. As expected, the ${ }^{\mathrm{DT}} \mathrm{CCS}\left(\mathrm{N}_{2}\right)$ values were observed to increase with the number $n$ of phosphoric acid molecules in the cluster. A graph of the ${ }^{\mathrm{DT}} \mathrm{CCS}\left(\mathrm{N}_{2}\right)$ vs the number of phosphoric acid molecules in the cluster is represented in Figure 3. We found that several functions could be fitted to our experimental values: a second order polynomial or a power function both produced an $\mathrm{R}^{2}$ of 0.998 .

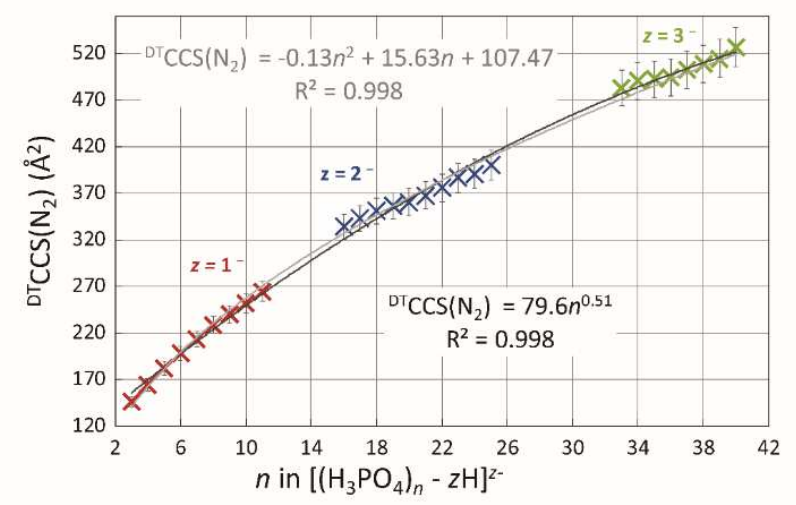

Figure 3. Graph of ${ }^{D T} \mathrm{CCS}\left(\mathrm{N}_{2}\right)\left(\AA^{2}\right)$ of phosphoric acid cluster ions vs the number of phosphoric acid molecules in the cluster. The error bars are set at $3 \%$ of the value.

\section{Travelling wave ion mobility of phosphoric acid cluster ions}

The ion mobility and mass spectra obtained with travelling wave ion mobility were found comparable to the results obtained with drift-tube ion mobility mass spectrometry but with a lower resolving power. Figure 4 shows the EIM spectra of $m / z$ values corresponding to singly charged phosphoric acid cluster ions from $\mathrm{P \# 3^{- }}$ to $\mathrm{P \# 8^{- }}$ and to a set of doubly (P\#18 ${ }^{2-}$ to $\left.\mathrm{P} \# 24^{2-}\right)$ and triply charged $\left(\mathrm{P} \# 35^{3-}\right.$ and $\left.\mathrm{P} \# 36^{3-}\right)$ cluster ions, at wave velocity of $350 \mathrm{~m} / \mathrm{s}$ and wave height $15 \mathrm{~V}$. The resolving power (calculated form the FWHM) of all ion mobility signals was around 17 for the signals of the singly charged cluster ions, 19 for the doubly charged cluster ions and 27 for the triply charged cluster ions. With such resolving power, only the singly charged cluster ions had their signals well separated for adjacent clusters with one phosphoric acid molecule difference in aggregation number. The signals from the EIM spectra of adjacent doubly and triply charged cluster ions all partially overlapped. The presence under each peak in the EIM spectra of unresolved precursor ions of higher cluster numbers that fragmented after the IMS separation cannot be completely ruled out. In this case, this could potentially result in shifts of the peak centroids. 


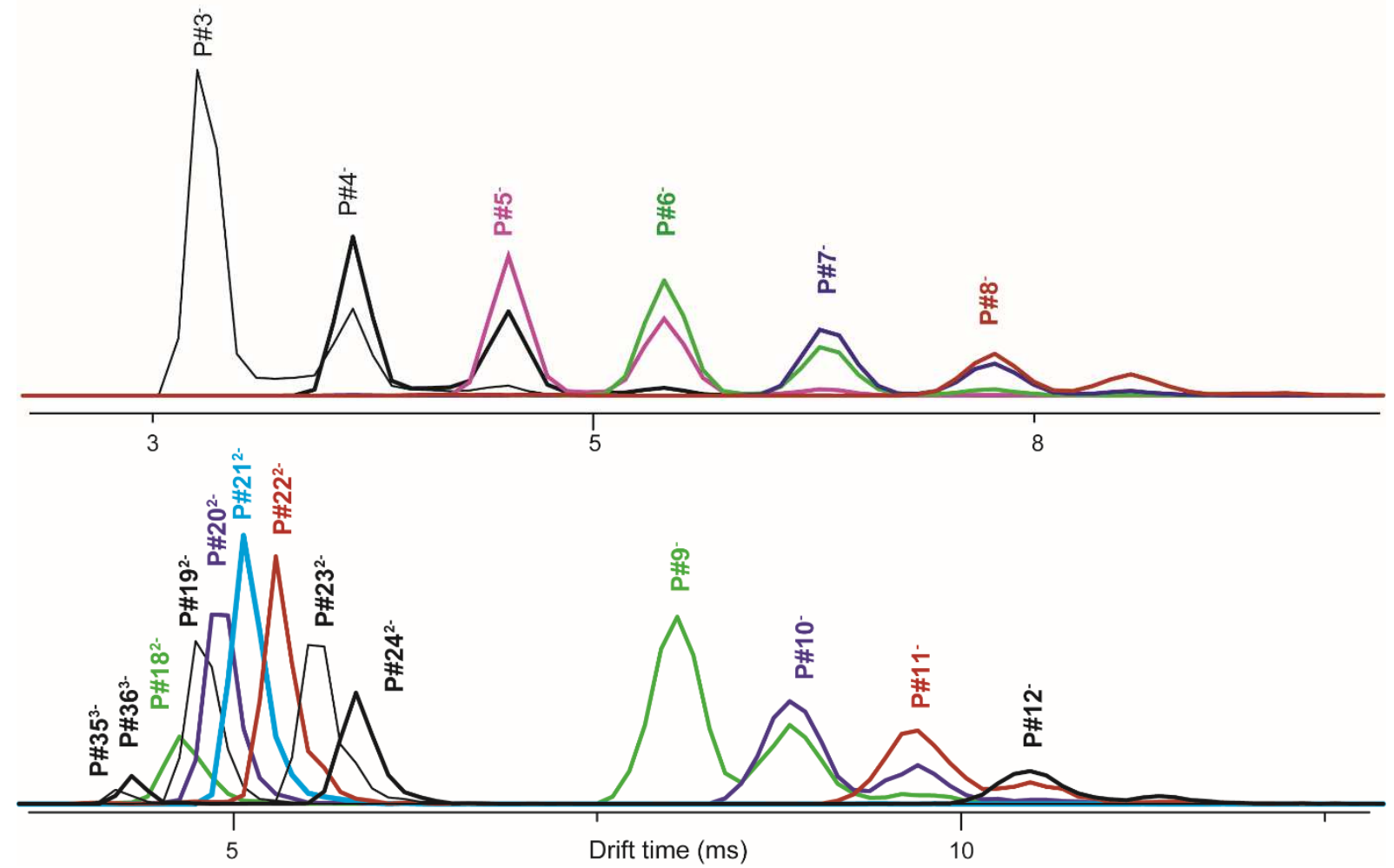

Figure 4. (a) EIM spectra of m/z 293 (thin black), 391 (thick black), 489 (magenta), 586 (green), 587(blue), and 685 (red) corresponding phosphoric acid cluster ions from $\left[\left(\mathrm{H}_{3} \mathrm{PO}_{4}\right)_{3} \mathrm{H}^{-}\right.$to $\left[\left(\mathrm{H}_{3} \mathrm{PO}_{4}\right)_{8}-\mathrm{H}^{-}\left(\mathrm{P \# 3^{- }}\right.\right.$ to $\left.\mathrm{P \# 8^{- }}\right)$ respectively. (b) EIM spectra

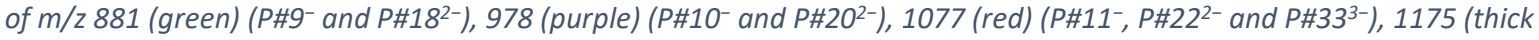

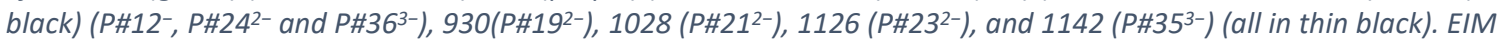
spectra are overlapped and were recorded at a wave velocity $350 \mathrm{~m} / \mathrm{s}$ and wave height $20 \mathrm{~V}$ for a m/z range of 50 to 4000 .

Indeed, as in the DTIMS-MS experiments, cluster dissociation in the transfer area between the ion mobility drift tube and the time-of-flight analyzer could be deduced from the comparison the EIM spectra of the $\mathrm{m} / \mathrm{z}$ values of clusters ions of adjacent aggregation numbers. Indeed, the EIM spectrum of $\mathrm{m} / \mathrm{z} 488.88$ (represented in magenta in Figure 5a),

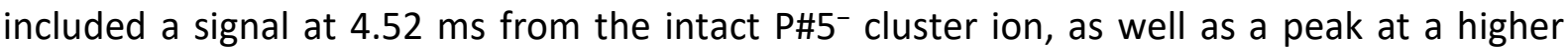
drift time (5.41 ms) corresponding to the $\mathrm{P} \# 6^{-}$cluster ion. A signal at $5.41 \mathrm{~ms}$ was also clearly visible in the EIM spectrum of $m / z 586.85$ (in green in figure 4a) which came here from the

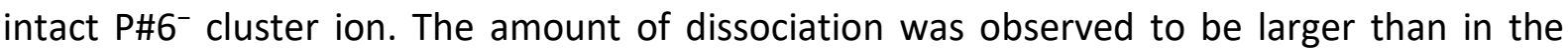
DTIMS-MS experiments, as the peak from the precursor ion had a relative intensity between 40 to $50 \%$ compared to the intact cluster ions. This proportion of precursor ion signal was observed to decrease less with increasing cluster size: the precursor signal from $\mathrm{P} \# 12^{-}$was still observed at $30 \%$ relative intensity compared to the intact $\mathrm{P} \# 11^{-}$cluster ion in the EIM spectrum of $m / z 1077$. For multiply charged cluster ions, the amount of dissociation was impossible to estimate as the signals of adjacent cluster ions overlapped. We nevertheless supposed the signals to be largely attributable to the intact cluster ions. Regardless of the amount of dissociation, we hypothesized that the intact clusters should have similar conformations to those observed in the DTIMS-MS experiments.

We did observe some differences as to the range of phosphoric acid cluster ions detected.

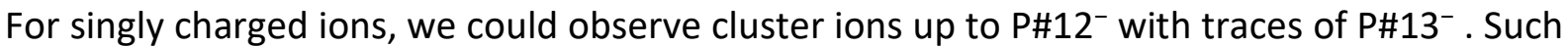
large singly charged cluster ions which were not well observed in our DTIMS-MS 
experiments. Conversely, $\mathrm{P} \# 17^{2-}$ was very low intensity and low signal/noise ratio in the EIM spectrum of $m / z 832$ in TWIMS-MS. The smallest doubly charged cluster ion distinguishable was $\mathrm{P} \# 18^{2-}$ (Figure $4 \mathrm{~b}$ ). For triply charged ions, $\mathrm{P} \# 33^{3-}$ and $\mathrm{P} \# 34^{3-}$ were not visible and the

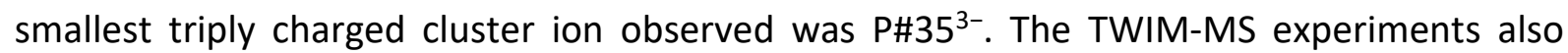
showed larger cluster ions with charges up to 6- (Figure S11-12). Out of the twenty-six cluster ions measured by DTIMS-MS, twenty-three could be used in the calibration of the TWIMS-MS. Nevertheless, we hypothesized that the intact cluster ions observed in both devices should have similar conformations.

For the calibration of the TWIMS, we chose to use a linearized version of the method which

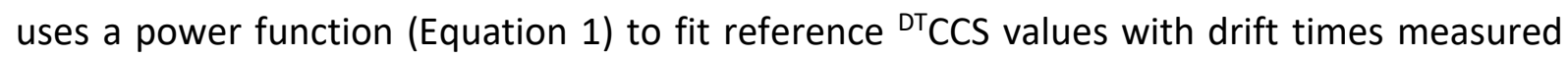
on the TWIM device for the reference compounds, as proposed by Smith et al. ${ }^{5}$ In equation $3, \Omega$ is defined as the CCS divided by the charge number $z$ and multiplied by the square root of the reduced mass $\mu$ of the ion and the drift gas $N_{2}$ (equation 2). $A$ and $B$ are found by fitting the curve of reference ${ }^{D T} C C S$ derived $\Omega^{\prime}$ values vs TWIMS drift times $t_{d}$. Here, we have linearized this equation by using natural logarithms, in order to have a linear regression where $\ln (\mathrm{A})$ and $\mathrm{B}$ are the intercept and the slope respectively (Equation 3 ). We did not apply any correction to the drift times and used the TWIMS drift time values given by a fit to a Gaussian function on the assigned peaks (with OriginPro 9.1).

$\Omega^{\prime}=A t_{D}^{B}$

$\Omega^{\prime}=\frac{\sqrt{\mu}}{z} \Omega$

$\ln \left(\Omega^{\prime}\right)=\ln A+B \ln \left(t_{D}\right)$

The resulting correlations are shown on Figure 5, for the three set of values obtained from the singly, doubly and triply charged phosphoric acid cluster ions. The determination coefficient $R^{2}$ observed for the singly charged phosphoric cluster ions was remarkably high with a value higher than 0.9999 . The determination coefficients $R^{2}$ were not as good for doubly and triply charged cluster ions with values of 0.998 and 0.939 respectively. A repeated experiment at $350 \mathrm{~m} / \mathrm{s}$ wave velocity and $20 \mathrm{~V}$ wave height led to similar results (Figure S13). 


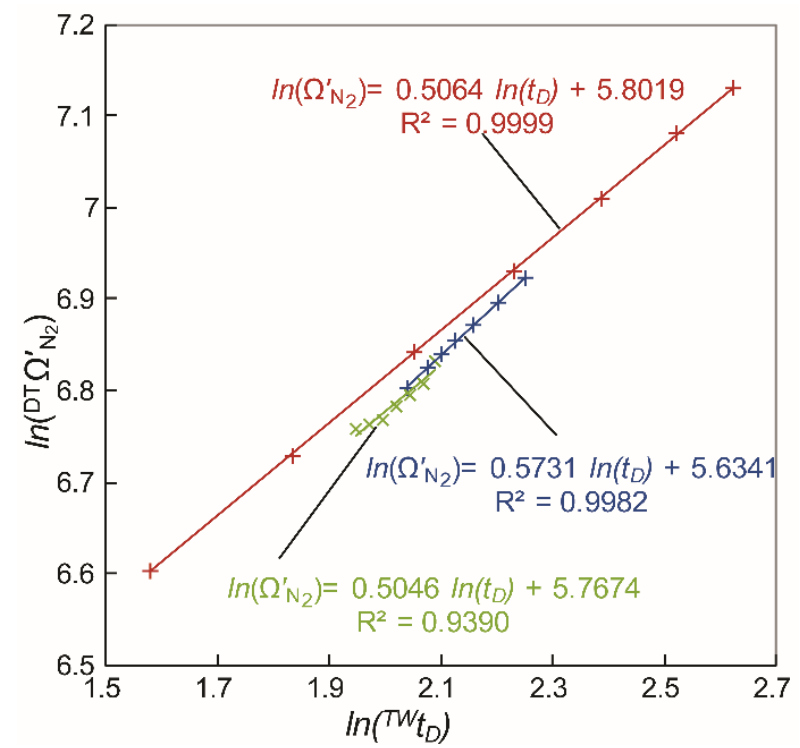

Figure 5. Calibration correlations obtained from singly charged (red), doubly charged (blue) and triply charged (green) phosphoric cluster anions and TWIM drift time values obtained with $350 \mathrm{~m} / \mathrm{s}$ IMS wave velocity and $15 \mathrm{~V}$ IMS wave height.

Note that these high determination coefficients were obtained with low wave velocities, which are the parameters for which good calibration correlations have been observed before by Zhong et al. ${ }^{40}$ Recently, Richardson et al, ${ }^{41}$ who studied velocity relaxation effects in TWIMS, noted calibration to have the highest $\mathrm{R}^{2}$ with low wave velocity. Finally, Mortensen et al ${ }^{42}$ who recently proposed a computational method to measure collision cross sections with TWIMS without experimental calibration noted that low wave velocities and gentle instrument settings should be used to minimize uncertainties in their method. Indeed, low wave velocities and gentle instrument setting in the TWIMS-MS were key parameters for the cluster ions to survive the ion mobility separation and ensure that ion conformations would be similar to the conformations in the DTIMS-MS experiments. We do not believe the ion source settings to be as important as the only effect was to change the range and abundance of the cluster ions detected. When the cluster ions enter the ion mobility device, intact cluster ions of given aggregation numbers are expected to adopt always the same isotropic conformations and growth. In fact, monitoring the shape of peaks and amount of dissociation from the EIM spectra of phosphoric acid clusters might help to achieve the desirable experimental conditions that minimize cleavage of hydrogen bonds and should thus preserve labile biomolecule conformations throughout the ion mobility device and during the transfer to the TOF analyzer.

We observed the multiply charged cluster ions led to different correlation functions compared to singly charged cluster ions. Indeed, both the intercept $\operatorname{In} A$ and slope $B$ from the multiply charged cluster ions differed by 13 to $30 \%$ compared to the values obtained from the singly charged cluster ions. Doubly and triply charged cluster ions both resulted in very similar correlation functions with intercepts and slopes that differed by less than $0.2 \%$. Such difference between the calibration curves obtained for TWIMS from multiply and singly charged ions has been observed before for positively charged ions by Gelb et al ${ }^{43}$ who 
recommend matching the charge states of the calibrant and analyte ions. They also recommended matching molecular classes.

With these calibrations, we proceeded to test the resulting accuracy on estimated ${ }^{\mathrm{TW}} \mathrm{CCS}\left(\mathrm{N}_{2}\right)$ values using a set of ten ions obtained from negative ions derived from polyalanine, dextran and the hexakis(fluoroalkoxy)phosphazine (HFAP) at $\mathrm{m} / \mathrm{z} 602$ from the Agilent tune mix, for which ${ }^{\mathrm{DT}} \mathrm{CCS}\left(\mathrm{N}_{2}\right)$ are published ${ }^{37,44,45}$ and are therefore often used as calibrants. These chosen test ions are all singly charged anions in the CCS range of the singly charged phosphoric acid cluster anions. To examine multiply charged anions, we also tested a set of five anions derived from polyoxometalates for which we had measured the ${ }^{\mathrm{DT}} \mathrm{CCS}\left(\mathrm{N}_{2}\right)$ on the Tofwerk instrument in a previous study. ${ }^{46}$ The results with $350 \mathrm{~m} / \mathrm{s}$ IMS wave velocity and $15 \mathrm{~V}$ IMS wave height are presented in Table 2 (and Table S3 for with $350 \mathrm{~m} / \mathrm{s}$ IMS wave velocity and $20 \mathrm{~V}$ IMS wave height). The ${ }^{\mathrm{TW}} \mathrm{CCS}\left(\mathrm{N}_{2}\right)$ were estimated using four different calibration correlations: the correlations obtained from the singly, doubly and triply charged phosphoric anions as three separate sets and one correlation from all phosphoric cluster anions assembled regardless of the charge state. The comparison of the values obtained from all these different calibrations showed that the ${ }^{\mathrm{TW}} \mathrm{CCS}\left(\mathrm{N}_{2}\right)$ differed by up to $20 \AA^{2}$ from one calibration to the other, with the highest difference observed for the multiply charged ions, with the largest CCS. In fact, a maximum relative difference of $6 \%$ was observed between the different calibration sets which was surprisingly low given the $20 \%$ difference observed for the $\ln (A)$ and $B$ values from the correlation functions.

Focusing on the values obtained using the set of singly charged cluster anions, we found the ${ }^{\mathrm{TW}} \mathrm{CCS}\left(\mathrm{N}_{2}\right)$ values of singly charged anions to be systematically higher by 9 to $11 \AA^{2}$ compared to published ${ }^{\mathrm{DT}} \mathrm{CCS}\left(\mathrm{N}_{2}\right)$ values, which amounts to 5 or $6 \%$ relative error, with the notable exception of $\left[\mathrm{Glc}_{2}-\mathrm{H}\right]^{-}$for which the ${ }^{\mathrm{TW}} \mathrm{CCS}\left(\mathrm{N}_{2}\right)$ showed only a $4 \AA^{2}(2 \%)$ difference compared to its ${ }^{\mathrm{DT}} \mathrm{CCS}\left(\mathrm{N}_{2}\right)$ value. Such 9 to $11 \AA^{2}$ discrepancy between ${ }^{\mathrm{DT}} \mathrm{CCS}\left(\mathrm{N}_{2}\right)$ and ${ }^{T W} \mathrm{CCS}\left(\mathrm{N}_{2}\right)$ using a high quality correlation must arise from a systemic error. An offset of $5 \AA^{2}$ on average has been observed before between the ${ }^{\mathrm{DT}} \mathrm{CCS}\left(\mathrm{N}_{2}\right)$ and ${ }^{{ }^{T W}} \operatorname{CCS}\left(\mathrm{N}_{2}\right)$ of lipids. ${ }^{47}$ Temperature could, in part, explain this bias. Litterature ${ }^{\mathrm{DT}} \mathrm{CCS}\left(\mathrm{N}_{2}\right)$ values for polyalanine ${ }^{47}$ were determined at room temperature and around $25^{\circ} \mathrm{C}$ for the tune mix ${ }^{12}$. For dextran ${ }^{45}$, the authors discuss the fact that ion temperature was uncertain. In fact, higher temperature decreases the value of the CCS because of the greater average speed of the gas molecules in the drift cell. ${ }^{48}$ Our larger values thus suggested that the ion temperature in our drift tube experiments was lower than during the experiments associated with the published ${ }^{\mathrm{DT}} \mathrm{CCS}\left(\mathrm{N}_{2}\right)$ values of polyalanine, dextran and the hexakis(fluoroalkoxy)phosphazine (HFAP) at $m / z 602$ from the Agilent tune mix, Another explanation may reside in the approximate nature of the Mason Schamp equation which is a zero field limit. Improvement of the equation have been studied by Hauck and Siems et al. ${ }^{49,50}$ They show how an increase in electric field strength may lead to larger CCS values.

The errors of the singly charged anions were slightly lower when the ${ }^{T W} \operatorname{CCS}\left(\mathrm{N}_{2}\right)$ were estimated using the other calibrations with higher or all charge states. The lower errors in this case, were most probably the result of two or more systematic errors that happened to compensate. These lower CCS values closer to the reference ${ }^{\mathrm{DT} C C S}$ could be the result of a 
smaller difference in temperature and electric field with the reference measurements. Indeed, multiply charged ions might be considered "hotter" due to the larger speeds resulting of their higher influence of the electric field.

Table 2. Accuracy test on ions from dextran, polyalanine, the hexakis(fluoroalkoxy)phosphazine at $\mathrm{m} / \mathrm{z} 602$ (Agilent tune mix) and polyoxometalate derived anions. Calibrations using singly, doubly triply charged phosphoric cluster anions are compared as well as the calibration obtained from ions of charge states. ${ }^{D T} \mathrm{CCS}\left(\mathrm{N}_{2}\right)$ values are reported from references ${ }^{37,44,45}$. Values in bold highlight the CCS measurement using calibration with reference ions of charges states matching that of the measured ions. TWIMS was carried out at $350 \mathrm{~m} / \mathrm{s}$ IMS wave velocity and $15 \mathrm{~V} I \mathrm{MS}$ wave height.

\begin{tabular}{|c|c|c|c|c|c|c|c|c|c|c|}
\hline \multirow[t]{2}{*}{ Ion } & \multirow[t]{2}{*}{$\begin{array}{l}{ }^{\mathrm{DT}} \mathrm{CCS}( \\
\left.\mathrm{N}_{2}\right) \\
\left(\AA^{2}\right)\end{array}$} & \multirow[t]{2}{*}{$m / z$} & \multicolumn{4}{|c|}{$\begin{array}{l}{ }^{T W} C C S\left(N_{2}\right)\left(\AA^{2}\right) \text { estimated with } \\
\text { different calibrations }\end{array}$} & \multicolumn{4}{|c|}{$\begin{array}{l}\triangle C C S / C C S \\
\text { with different calibrations } \\
\text { (\%) }\end{array}$} \\
\hline & & & $1-$ & $2-$ & $3-$ & $\begin{array}{l}\text { all } \\
\text { charge }\end{array}$ & $1-$ & $2-$ & 3- & $\begin{array}{l}\text { all } \\
\text { charge }\end{array}$ \\
\hline$\left[(\mathrm{Ala})_{3}-\mathrm{H}\right]^{-}$ & 150.8 & 230.2 & 159.5 & 151.3 & 152.2 & 154.3 & 6 & 0 & 1 & 2 \\
\hline$\left[(\mathrm{Ala})_{4}-\mathrm{H}\right]^{-}$ & 165.5 & 301.3 & 175.3 & 168.7 & 168.3 & 170.7 & 6 & 2 & 2 & 3 \\
\hline$\left[(\mathrm{Ala})_{5}-\mathrm{H}\right]^{-}$ & 180.6 & 372.4 & 191.4 & 186.6 & 184.9 & 187.5 & 6 & 3 & 2 & 4 \\
\hline HFAP $m / z 602$ & 180.1 & 602.0 & 190.3 & 185.7 & 183.9 & 186.5 & 6 & 3 & 2 & 4 \\
\hline$\left[(\mathrm{Ala})_{6}-\mathrm{H}\right]^{-}$ & 196.2 & 443.5 & 207.2 & 204.4 & 201.2 & 204.2 & 6 & 4 & 3 & 4 \\
\hline$\left[(\mathrm{Ala})_{7}-\mathrm{H}\right]^{-}$ & 210.3 & 514.6 & 221.4 & 220.5 & 216.0 & 219.1 & 5 & 5 & 3 & 4 \\
\hline$\left[(\mathrm{Ala})_{8}-\mathrm{H}\right]^{-}$ & 223.7 & 585.6 & 234.4 & 235.3 & 229.5 & 232.9 & 5 & 5 & 3 & 4 \\
\hline$\left[(\mathrm{Glc})_{2}-\mathrm{H}\right]^{-}$ & 174.6 & 341.1 & 178.3 & 172.1 & 171.5 & 173.9 & 2 & -1 & -2 & -0.4 \\
\hline$\left[(\mathrm{Glc})_{3}-\mathrm{H}\right]^{-}$ & 202.3 & 503.2 & 213.3 & 211.3 & 207.6 & 210.6 & 5 & 4 & 3 & 4 \\
\hline$\left[(\mathrm{Glc})_{4}-\mathrm{H}\right]^{-}$ & 234.0 & 665.2 & 243.6 & 245.9 & 239.1 & 242.6 & 4 & 5 & 2 & 4 \\
\hline$\left[\mathrm{PMO}_{12} \mathrm{O}_{40}+\mathrm{TBA}\right]^{2-}$ & 348 & 1033.0 & 353.8 & 342.7 & 340.8 & 345.6 & 2 & -2 & -2 & -0.7 \\
\hline$\left[\mathrm{PW}_{12} \mathrm{O}_{40}+\mathrm{TBA}\right]^{2-}$ & 349 & 1559.7 & 356.1 & 345.4 & 343.2 & 348.1 & 2 & -1 & -2 & -0.3 \\
\hline$\left[\mathrm{P}_{2} \mathrm{~W}_{18} \mathrm{O}_{62}+\mathrm{TBA}+2 \mathrm{H}\right]^{3-}$ & 438 & 1535.8 & 451.7 & 428.4 & 430.9 & 436.9 & 3 & -2 & -2 & -0.2 \\
\hline$\left[\mathrm{P}_{2} \mathrm{~W}_{18} \mathrm{O}_{62}+2 \mathrm{TBA}+\mathrm{H}\right]^{3-}$ & 481 & 1617.4 & 492.1 & 472.2 & 471.9 & 478.6 & 2 & -2 & -2 & -0.5 \\
\hline$\left[\mathrm{P}_{2} \mathrm{~W}_{18} \mathrm{O}_{62}+3 \mathrm{TBA}\right]^{3-}$ & 520 & 1696.9 & 530.9 & 514.6 & 511.5 & 518.8 & 2 & -1 & -2 & 0.2 \\
\hline
\end{tabular}

The accuracy of the measurement of the polyoxometalate derived anions were quite good with relative errors of $2 \%$ or less, which represent differences of $-10 \AA^{2}$ between ${ }^{\mathrm{TW}} \mathrm{CCS}\left(\mathrm{N}_{2}\right)$ and ${ }^{\mathrm{DT}} \mathrm{CCS}\left(\mathrm{N}_{2}\right)$ for these ions of higher CCS values. This result was expected considering that the ${ }^{\mathrm{DT}} \mathrm{CCS}\left(\mathrm{N}_{2}\right)$ measurement were carried out on the same instrument at a similar temperature (the CCS polyoxometalate derived anions were measured at $31^{\circ} \mathrm{C}$ ). Any systematic error arising from instrumental conditions should therefore be absent. It can be noted that structurally very different compounds could be used here as reference for CCS measurements which is not the commonly recommended practice. ${ }^{15}$

\section{CONCLUSION}


We herein presented the first determination of twenty-six new ${ }^{\mathrm{DT}} \mathrm{CCS}\left(\mathrm{N}_{2}\right)$ for phosphoric clusters anions. The values come in three sets: singly deprotonated clusters with an aggregation numbers 3 to 11, doubly charged clusters anions with aggregation numbers 17 to 25 and triply charged phosphoric acid cluster anions with aggregation numbers 33 to 40 . The ${ }^{\mathrm{DT}} \mathrm{CCS}\left(\mathrm{N}_{2}\right)$ ranged from three to 146 to $264 \AA^{2}, 337$ to $402 \AA^{2}$ and 486 to $530 \AA^{2}$, respectively. Reduced mobilities $\mathrm{K}_{0}$ range from 0.77 to $1.4 \mathrm{~cm}^{2} \mathrm{~V}^{-1} \mathrm{~s}^{-1}$ for singly charged cluster anions. Doubly and triply charged cluster anions cover only $30 \%$ and $16 \%$ of that range (1.177 to $1.006 \mathrm{~cm}^{2} \mathrm{~V}^{-1} \mathrm{~s}^{-1}$ and 1.250 to $1.0143 \mathrm{~cm}^{2} \mathrm{~V}^{-1} \mathrm{~s}^{-1}$ ).

Although these measurements will need to be further reproduced on different instruments to establish these ${ }^{\mathrm{DT}} \mathrm{CCS}\left(\mathrm{N}_{2}\right)$ more firmly and complete them, we found these ${ }^{\mathrm{DT}} \mathrm{CCS}\left(\mathrm{N}_{2}\right)$ values to be self-consistent and that the three sets combined could be fitted to a power function with an exponent of 0.51 .

The values of ${ }^{\mathrm{DT}} \mathrm{CCS}\left(\mathrm{N}_{2}\right)$ of the singly charged phosphoric acid anions were found remarkably well correlated (determination coefficient $R^{2}$ above 0.9999 ) to the drift times measured on a TWIMS-MS device thereby confirming that the conformation of the phosphoric acid cluster ions were comparable in the two very different DTIMS and TWIMS devices and they thus could be well suited compounds for calibration. Indeed, we expect that a given cluster ion will dissociate rather than undergo significant conformational change thus guarantying that a given cluster ion will present a unique and reproducible CCS value.

Comparing the correlations obtained in TWIMS using the multiply and singly charged anions, we observed that there was a charge state effect on the calibration. Accuracy tests on singly charged ions evidenced a bias of 9 to $11 \AA^{2}$ for ${ }^{T W} \operatorname{CCS}\left(N_{2}\right)$ values compared to reference ${ }^{\mathrm{DT}} \mathrm{CCS}\left(\mathrm{N}_{2}\right)$ values of ions from polyalanine, dextran and the hexakis(fluoroalkoxy)phosphazine at $m / z$ 602. Note that although absolute values were shifted, CCS differences were preserved.

This bias was most probably instrument-related. Indeed, the accuracy test on polyoxometalate derived anions, for which ${ }^{\mathrm{DT}} \mathrm{CCS}\left(\mathrm{N}_{2}\right)$ were measured on the same instrument showed errors for the ${ }^{\mathrm{TW}} \mathrm{CCS}\left(\mathrm{N}_{2}\right)$ values below $2 \%$, even though the compounds were structurally very different from the phosphoric acid cluster anions. We could not identify the cause of the bias for polyalanine, dextran and the hexakis(fluoroalkoxy)phosphazine at $\mathrm{m} / \mathrm{z} 602$ within this study. Temperature and field strengths could play a role; a compound class effect may also intervene although that did not seem to be the case with polyoxometalates.

Collision cross section values for singly and multiply charged anions can be obtained with a single experiment using one very simple and easily available compound. One drawback is that phosphoric acid cluster ions are very fragile and care must be taken to avoid dissociation between the drift tube and the mass analyzer, as such dissociations can lead to difficulties in the assignment of the signals in the ion mobility spectra. However, comparison of the extracted ion mobility spectra of the $\mathrm{m} / \mathrm{z}$ values of clusters ions of adjacent aggregation numbers enables unambiguous ion mobility peak attribution and allows a pattern of drift times depending on the aggregation number and charge state to be 
gathered. Moreover, the lability of phosphoric acid cluster ions could be turned to an advantage because it enables to visualize and monitor the cleavage of hydrogen bonds and thus help achieve the desirable experimental conditions that should preserve labile biomolecule conformations.

\section{ELECTRONIC SUPPLEMENTARY INFORMATION}

Voltage parameters on the Tofwerk IMS-TOF and SYNAPT G2 instruments, isotopic distribution of phosphoric cluster ions, a two-dimensional IMS-MS color map of the ESI in the negative ion mode of a phosphoric acid solution, extracted ion mobility spectra and graphs of the drift time $v s$ the reciprocal of the potential difference in the ion mobility drift tube, $m / z$ vs drift time maps of the TWIMS MS analyses, graph of the calibration correlation and accuracy tests with $350 \mathrm{~m} / \mathrm{s}$ IMS wave velocity and $20 \mathrm{~V}$ IMS wave height.

\section{ACKNOWLEDGMENTS}

The authors gratefully acknowledge the Région Normandie, the Labex SynOrg (ANR-11-LABX-0029) and the European Regional Development Fund (ERDF 31708) for financial support. HL thanks Sébastien Hupin for the TWIMS-MS data of polyalanine, dextran and the polyoxometalates, and Valentina Calabrese for helpful discussions.

\section{REFERENCES}

1. Campuzano ID, Lippens JL. Ion mobility in the pharmaceutical industry: an established biophysical technique or still niche? Curr Opin Chem Biol 2018;42:147-159. doi: 10.1016/j.cbpa.2017.11.008.

2. May JC, McLean JA. Ion mobility-mass spectrometry: time-dispersive instrumentation. Anal Chem 2015;87(3):1422-1436. doi: 10.1021/ac504720m.

3. Pringle SD, Giles K, Wildgoose JL, Williams JP, Slade SE, Thalassinos K, Bateman RH, Bowers $M T$, Scrivens JH. An investigation of the mobility separation of some peptide and protein ions using a new hybrid quadrupole/travelling wave IMS/oa-ToF instrument. Int. J. Mass Spectrom. 2007;261:1-12. doi: 10.1016/j.ijms.2006.07.021.

4. Ridgeway ME, Lubeck M, Jordens J, Mann M, Park MA. Trapped ion mobility spectrometry: A short review. Int. J. Mass Spectrom. 2018;425:22-35. doi: 10.1016/j.ijms.2018.01.006.

5. Smith DP, Knapman TW, Campuzano I, Malham RW, Berryman JT, Radford SE, Ashcroft AE. Deciphering drift time measurements from travelling wave ion mobility spectrometry-mass spectrometry studies. Eur J Mass Spectrom 2009;15(2):113-130. doi: 10.1255/ejms.947.

6. Ruotolo BT, Benesch JL, Sandercock AM, Hyung SJ, Robinson CV. Ion mobility-mass spectrometry analysis of large protein complexes. Nat Protoc 2008;3(7):1139-1152. doi: 10.1038/nprot.2008.78.

7. Hernandez DR, Debord JD, Ridgeway ME, Kaplan DA, Park MA, Fernandez-Lima F. Ion dynamics in a trapped ion mobility spectrometer. Analyst 2014;139(8):1913-1921. doi: 10.1039/c3an02174b.

8. Lippens JL, Ranganathan SV, D'Esposito RJ, Fabris D. Modular calibrant sets for the structural analysis of nucleic acids by ion mobility spectrometry mass spectrometry. Analyst 2016;141(13):4084-4099. doi: 10.1039/c6an00453a.

9. May JC, Morris CB, McLean JA. Ion Mobility Collision Cross Section Compendium. Anal Chem 2017;89(2):1032-1044. doi: 10.1021/acs.analchem.6b04905. 
10. Forsythe JG, Petrov AS, Walker CA, Allen SJ, Pellissier JS, Bush MF, Hud NV, Fernández FM. Collision cross section calibrants for negative ion mode traveling wave ion mobility-mass spectrometry. Analyst 2015;140:6853-6861. doi: 10.1039/C5AN00946D.

11. Hofmann J, Struwe WB, Scarff CA, Scrivens JH, Harvey DJ, Pagel K. Estimating Collision Cross Sections of Negatively Charged N-Glycans using Travelling Wave lon Mobility-Mass Spectrometry. Anal. Chem. 2014):140930111345006. doi: 10.1021/ac5028353.

12. Stow SM, Causon TJ, Zheng X, Kurulugama RT, Mairinger T, May JC, Rennie EE, Baker ES, Smith RD, McLean JA, Hann S, Fjeldsted JC. An Interlaboratory Evaluation of Drift Tube Ion Mobility-Mass Spectrometry Collision Cross Section Measurements. Anal Chem 2017;89:9048-9055. doi: 10.1021/acs.analchem.7b01729.

13. Bush MF, Campuzano ID, Robinson CV. Ion mobility mass spectrometry of peptide ions: effects of drift gas and calibration strategies. Anal Chem 2012;84(16):7124-7130. doi: 10.1021/ac3014498.

14. Haler JRN, Kune C, Massonnet P, Comby-Zerbino C, Jordens J, Honing M, Mengerink Y, Far J, De Pauw E. Comprehensive Ion Mobility Calibration: Poly(ethylene oxide) Polymer Calibrants and General Strategies. Anal Chem 2017;89(22):12076-12086. doi: 10.1021/acs.analchem.7b02564.

15. Gabelica V, Shvartsburg AA, Afonso C, Barran P, Benesch JLP, Bleiholder C, Bowers MT, Bilbao A, Bush MF, Campbell JL, Campuzano IDG, Causon T, Clowers BH, Creaser CS, De Pauw E, Far J, Fernandez-Lima F, Fjeldsted JC, Giles K, Groessl M, Hogan CJ, Jr., Hann S, Kim HI, Kurulugama RT, May JC, McLean JA, Pagel K, Richardson K, Ridgeway ME, Rosu F, Sobott F, Thalassinos K, Valentine SJ, Wyttenbach T. Recommendations for reporting ion mobility Mass Spectrometry measurements. Mass Spectrom Rev 2019. doi: 10.1002/mas.21585.

16. Zhang D, Cooks RG. Doubly charged cluster ions $\left[(\mathrm{NaCl})_{m}(\mathrm{Na})_{2}\right]^{2+}$ : magic numbers, dissociation, and structure. Int. J. Mass Spectrom. 2000;195-196(0):667-684. doi: 10.1016/s1387-3806(99)00184-0.

17. Lermyte F, Sobott F. A broader view on ion heating in traveling-wave devices using fragmentation of $\mathrm{Csl}$ clusters and extent of $\mathrm{H}$ migration as molecular thermometers. Analyst 2017;142(18):3388-3399. doi: 10.1039/c7an00161d.

18. Hao C, March RE. Electrospray ionization tandem mass spectrometric study of salt cluster ions: part 2--salts of polyatomic acid groups and of multivalent metals. J Mass Spectrom 2001;36(5):509-521. doi: 10.1002/jms.150.

19. Galhena AS, Jones CM, Wysocki VH. Influence of cluster size and ion activation method on the dissociation of cesium iodide clusters. Int. J. Mass Spectrom. 2009;287(1-3):105-113. doi: 10.1016/j.ijms.2009.03.009.

20. Sobott F, Hernandez H, McCammon MG, Tito MA, Robinson CV. A tandem mass spectrometer for improved transmission and analysis of large macromolecular assemblies. Anal Chem 2002;74(6):1402-1407. doi: 10.1021/ac0110552.

21. Fernandez-Lima FA, Becker C, Gillig K, Russell WK, Nascimento MA, Russell DH. Experimental and theoretical studies of $(\mathrm{Csl})_{n} \mathrm{Cs}^{+}$cluster ions produced by $355 \mathrm{~nm}$ laser desorption ionization. J Phys Chem A 2008;112(44):11061-11066. doi: 10.1021/jp8047086.

22. Ouyang $\mathrm{H}$, Larriba-Andaluz $\mathrm{C}$, Oberreit DR, Hogan $\mathrm{CJ}$, Jr. The collision cross sections of iodide salt cluster ions in air via differential mobility analysis-mass spectrometry. J Am Soc Mass Spectrom 2013;24(12):1833-1847. doi: 10.1007/s13361-013-0724-8.

23. Ohshimo K, Takahashi T, Moriyama R, Misaizu F. Compact non-rock-salt structures in sodium fluoride cluster ions at specific sizes revealed by ion mobility mass spectrometry. J Phys Chem A 2014;118(43):9970-9975. doi: 10.1021/jp5061396.

24. Ku BK, de la Mora JF. Relation between Electrical Mobility, Mass, and Size for Nanodrops 1$6.5 \mathrm{~nm}$ in Diameter in Air. Aerosol Sci Technol 2009;43(3):241-249. doi: 10.1080/02786820802590510. 
25. Larriba C, Hogan CJ, Attoui M, Borrajo R, Garcia JF, de la Mora JF. The Mobility-Volume Relationship below $3.0 \mathrm{~nm}$ Examined by Tandem Mobility-Mass Measurement. Aerosol Sci Technol 2011;45(4):453-467. doi: 10.1080/02786826.2010.546820.

26. Larriba-Andaluz C, Hogan CJ, Jr. Collision cross section calculations for polyatomic ions considering rotating diatomic/linear gas molecules. J Chem Phys 2014;141(19):194107. doi: 10.1063/1.4901890.

27. Larriba-Andaluz C, Fernandez-Garcia J, Ewing MA, Hogan CJ, Jr., Clemmer DE. Gas molecule scattering \& ion mobility measurements for organic macro-ions in He versus $\mathrm{N}_{2}$ environments. Phys Chem Chem Phys 2015;17(22):15019-15029. doi: 10.1039/c5cp01017a.

28. Ohshimo K, Komukai T, Moriyama R, Misaizu F. Isomer separation of iron oxide cluster cations by ion mobility mass spectrometry. J Phys Chem A 2014;118(22):3899-3905. doi: 10.1021/jp5015687.

29. Ohshimo K, Azuma S, Komukai T, Moriyama R, Misaizu F. Structures and CO-Adsorption Reactivities of Nickel Oxide Cluster Cations Studied by lon Mobility Mass Spectrometry. J Phys Chem C 2015;119(20):11014-11021. doi: 10.1021/jp5115674.

30. Ohshimo K, Norimasa N, Moriyama R, Misaizu F. Stable compositions and geometrical structures of titanium oxide cluster cations and anions studied by ion mobility mass spectrometry. J Chem Phys 2016;144(19):194305. doi: 10.1063/1.4949269.

31. Wu JW, Moriyama R, Tahara H, Ohshimo K, Misaizu F. Compositions and Structures of Vanadium Oxide Cluster Ions $\mathrm{V}_{m} \mathrm{O}_{n}{ }^{(+-)}(m=2-20)$ Investigated by Ion Mobility Mass Spectrometry. J Phys Chem A 2016;120(21):3788-3796. doi: 10.1021/acs.jpca.6b03403.

32. Moriyama R, Sato R, Nakano M, Ohshimo K, Misaizu F. Geometrical Structures of Gas Phase Chromium Oxide Cluster Anions Studied by Ion Mobility Mass Spectrometry. J Phys Chem A 2017;121(30):5605-5613. doi: 10.1021/acs.jpca.7b02431.

33. Wu JWJ, Moriyama R, Nakano M, Ohshimo K, Misaizu F. Compositions and structures of niobium oxide cluster ions, $\mathrm{Nb}_{m} \mathrm{O}_{n}{ }^{(+-)},(m=2-12)$, revealed by ion mobility mass spectrometry. Phys Chem Chem Phys 2017;19(36):24903-24914. doi: 10.1039/c7cp04017b.

34. Lavanant $\mathrm{H}$, Tognetti V, Afonso C. Traveling Wave lon Mobility Mass Spectrometry and $A b$ Initio Calculations of Phosphoric Acid Clusters. J Am Soc Mass Spectrom 2014;25(4):572-580. doi: 10.1007/s13361-013-0818-3.

35. Kwasnik M, Fuhrer K, Gonin M, Barbeau K, Fernandez FM. Performance, resolving power, and radial ion distributions of a prototype nanoelectrospray ionization resistive glass atmospheric pressure ion mobility spectrometer. Anal Chem 2007;79(20):7782-7791. doi: 10.1021/ac071226o.

36. Mason EA, Schamp HW. Mobility of gaseous lons in weak electric fields. Ann Phys 1958;4(3):233-270. doi: 10.1016/0003-4916(58)90049-6.

37. Stow SM, Causon TJ, Zheng X, Kurulugama RT, Mairinger T, May JC, Rennie EE, Baker ES, Smith RD, McLean JA, Hann S, Fjeldsted JC. An Interlaboratory Evaluation of Drift Tube Ion Mobility-Mass Spectrometry Collision Cross Section Measurements. Anal Chem 2017;89(17):9048-9055. doi: 10.1021/acs.analchem.7b01729.

38. Hogan CJ, Jr., Fernandez de la Mora J. Tandem ion mobility-mass spectrometry (IMS-MS) study of ion evaporation from ionic liquid-acetonitrile nanodrops. Phys Chem Chem Phys 2009;11(36):8079-8090. doi: 10.1039/b904022f.

39. Hogan CJ, Jr., Fernandez de la Mora J. Ion-pair evaporation from ionic liquid clusters. J Am Soc Mass Spectrom 2010;21(8):1382-1386. doi: 10.1016/j.jasms.2010.03.044.

40. Zhong Y, Hyung SJ, Ruotolo BT. Characterizing the resolution and accuracy of a secondgeneration traveling-wave ion mobility separator for biomolecular ions. Analyst 2011;136(17):3534-3541. doi: 10.1039/c0an00987c.

41. Richardson K, Langridge $D$, Giles K. Fundamentals of travelling wave ion mobility revisited: I. Smoothly moving waves. Int J Mass Spectrom 2018;428:71-80. doi: 10.1016/j.ijms.2018.03.007. 
42. Mortensen DN, Susa AC, Williams ER. Collisional Cross-Sections with T-Wave Ion Mobility Spectrometry without Experimental Calibration. J Am Soc Mass Spectrom 2017;28(7):12821292. doi: 10.1007/s13361-017-1669-0.

43. Gelb AS, Jarratt RE, Huang Y, Dodds ED. A study of calibrant selection in measurement of carbohydrate and peptide ion-neutral collision cross sections by traveling wave ion mobility spectrometry. Anal Chem 2014;86(22):11396-11402. doi: 10.1021/ac503379e.

44. Forsythe JG, Petrov AS, Walker CA, Allen SJ, Pellissier JS, Bush MF, Hud NV, Fernandez FM. Collision cross section calibrants for negative ion mode traveling wave ion mobility-mass spectrometry. Analyst 2015;140(20):6853-6861. doi: 10.1039/c5an00946d.

45. Hofmann J, Struwe WB, Scarff CA, Scrivens JH, Harvey DJ, Pagel K. Estimating collision cross sections of negatively charged $\mathrm{N}$-glycans using traveling wave ion mobility-mass spectrometry. Anal Chem 2014;86(21):10789-10795. doi: 10.1021/ac5028353.

46. Hupin S, Lavanant H, Renaudineau S, Proust A, Izzet G, GroessI M, Afonso C. A calibration framework for the determination of accurate collision cross sections of polyanions using polyoxometalate standards. Rap Commun Mass Spectrom 2018;32(19):1703-1710 (doi: 10.1002/rcm.8230)

47. GroessI M, Graf S, Knochenmuss R. High resolution ion mobility-mass spectrometry for separation and identification of isomeric lipids. Analyst 2015;140(20):6904-6911. doi: 10.1039/c5an00838g.

48. Revercomb HE, Mason EA. Theory of plasma chromatography/gaseous electrophoresis. Review. Anal Chem 1975;47:970-983. doi:

49. Siems WF, Viehland LA, Hill HH. Correcting the fundamental ion mobility equation for field effects. Analyst 2016;141(23):6396-6407. doi: 10.1039/c6an01353h.

50. Hauck BC, Siems WF, Harden CS, McHugh VM, Hill HH, Jr. Determination of E/N Influence on $\mathrm{K}_{0}$ Values within the Low Field Region of Ion Mobility Spectrometry. J Phys Chem A 2017;121(11):2274-2281. doi: 10.1021/acs.jpca.6b12331. 